\title{
Analysis for Thermal Characteristics of High-Speed Angular Contact Ball Bearing under Different Preload
}

\author{
Xiaoping $\mathrm{Li}^{1,2, \mathrm{a}^{*}}$, Yujun Xue $\mathrm{X}^{1,2, \mathrm{~b}}$, Yongjian $\mathrm{Yu}^{1,2, \mathrm{c}}$, Donghong $\mathrm{Si}^{1,2, \mathrm{~d}}$ and \\ Dongliang $\mathrm{Li}^{1,2, \mathrm{e}}$ \\ ${ }^{1}$ Henan University of Science and Technology, Luoyang 471003, China \\ ${ }^{2}$ Henan Key Laboratory of Modern Mechanical Design and Transmission System, Luoyang 471003, \\ China \\ a1101229607@qq.com, bxue_yujun@163.com, cyuyongjian2008@126.com, \\ d13592029798@139.com, elidongliang266@163.com
}

*The Corresponding Author

Keywords: Angular contact ball bearing; Preload; Thermal analysis; Numerical simulation

\begin{abstract}
A large amount of heat is produced due to the friction between components within the bearing, resulting in an increase in temperature of the bearing system. The value of the preload directly affects the temperature of the bearing, and will affect the performance of bearing. Based on ball bearing of quasi-statics and thermal analysis, the heat generation of the high speed angular contact ball bearing is calculated and analyzed under different preload, rotation speed and contact angle. The temperature distribution of the bearing under steady state condition is obtained by using ANSYS for the numerical simulation of the bearing different conditions, and the influence rule of preload on heat generation of bearing is given. The research results provide a reference for the temperature distribution of rolling bearing and its application research.
\end{abstract}

\section{Introduction}

Angular contact ball bearing can bear radial load and axial load at the same time, and can work at a high speed. Because of the friction between its internal components, high speed angular contact ball bearings will generate a lot of heat, which will have a great impact on the performance and stability of bearing. Liu and Bian analyzed the effect of load and rotation speed on bearing temperature rise by ANASYS [1,2]. Yu and Chen consideration of thermal contact resistance, influence of rotation speed and load on temperature field of angular contact ball bearing is studied [3,4]. Many scholars analyzed the effect of loading conditions, coupling effect and material on angular contact ball bearing temperature rise [5,6,7]. The preload of the angular contact ball bearing will also affect the working performance and life of the bearing. Jiang analyzed the working principle of the bearing preload, gave the principle of preload selection and the calculation method to determine the preload [8]. Li studied the application of preload on angular contact ball bearing [9].

The above research mainly focuses on the research of the influence of the rotating speed, load and lubrication on the bearing temperature. However, there are few studies of the effect of preload on the temperature of angular contact ball bearing. In this paper, a heat generation model of contact angle ball bearing is established, and the influence of rotation speed and contact angle on thermal characteristics of bearings under different preload is studied.

\section{Calculation of Heat Generation and Heat Transfer of Angular Contact Ball Bearing}

The preload of the bearings can be divided into two ways: radial pretension and axial pretension. The axial pretension is divided into fix-position pretension and fix-pressure pretension. The relative position of the fix-position pretension bearing will not change during the working process. Due to the change of working temperature, the size of the shaft, bearing seat and the size of the locating part of the bearing will be changed. Therefore, it will directly affect the change of the bearing preload. When the bearing adopts fix-pressure pretension, the value of the preload is determined by 
the preload device itself, so its value is not changed mostly, and it is not affected by the working temperature. The object of this study is the angular contact ball bearing, so the fix-pressure pretension is adopted.

As for the thermal analysis of rolling bearings, the heat transfer theory and the temperature distribution of the bearing system are studied mainly by the theory of heat transfer. The temperature of the bearing depends on the heat of its own and the heat dissipation of the system. The heat source of the bearing mainly comes from the friction between the parts, in which the heat generation is converted mainly through the friction torque. The power loss of the bearing is eventually dissipated by heat conduction, convection heat transfer and thermal radiation. The convection heat transfer between the surfaces of parts of the bearing system and air, oil-air mixture are an important form of heat transfer that must be considered.

Calculation of Heat Generation of Angular Contact Ball Bearing. The bearing material is used GCr15, the environmental temperature is $22^{\circ} \mathrm{C}$, and Table 1 is bearing parameter. The preload force is added to the outer ring of the bearing. Heat source calculation is the basis for studying the temperature rise of the bearing, and the friction heating of bearing is the main heat source of angular contact ball bearing. The calorific value of the bearing is caused by the friction torque of the bearing. The power loss of the rolling bearing is the product of the friction torque and the rotational speed, and the bearing temperature rise is closely related to the friction torque.

Table 1 Bearing parameters

\begin{tabular}{ccc}
\hline Parameter & Symbol & Value \\
\hline Outside diameter & $D$ & $150 \mathrm{~mm}$ \\
Internal diameter & $d$ & $100 \mathrm{~mm}$ \\
Bearing width & $B$ & $24 \mathrm{~mm}$ \\
Pitch diameter & $d_{\mathrm{m}}$ & $125 \mathrm{~mm}$ \\
Roller diameter & $D_{\mathrm{W}}$ & $15.874 \mathrm{~mm}$ \\
Number of rolling elements & $\mathrm{Z}$ & 20 \\
\hline
\end{tabular}

Heating calculation of bearing is:

$H=1.047 \times 10^{-4} n M$

Where, $(H)$-Heating of bearing; $(n)$-rotation speed; $(M)$-friction torque

The friction torque of the bearing is:

$M=M_{0}+M_{1}$

Where, $\left(M_{0}\right)$-friction torque related to bearing type, rotation speed, and lubricant properties; $\left(M_{1}\right)$-friction torque related to load

$$
\begin{array}{ll}
\text { When } v n \geq 2000, & M_{0}=10^{-7} f_{0}(v n)^{2 / 3} d_{m}^{3} \\
\text { When } v n<2000, & M_{0}=160 \times 10^{-7} f_{0} d_{m}^{3}
\end{array}
$$

$M_{1}=f_{1} p_{1} d_{m}$

Where, $\left(f_{0}\right)$-coefficient related to bearing type and lubrication method; $\left(P_{1}\right)$-preload of angular contact ball bearing; $(v)$-kinematic viscosity

For angular contact ball bearing:

$$
f_{1}=0.0013\left(\frac{F_{s}}{C_{s}}\right)^{0.33}
$$




$$
C_{s}=\varphi_{s} \bullet Z \bullet D_{W}^{2} \bullet \cos \alpha
$$

Where, $\left(f_{1}\right)$-coefficient related to bearing type and load; $\left(F_{\mathrm{s}}\right)$-equivalent static load; $\left(C_{\mathrm{s}}\right)$-static load rating; $\left(\varphi_{\mathrm{s}}\right)$ - load rating factor; $(\alpha)$-contact angle of angular contact ball bearing.

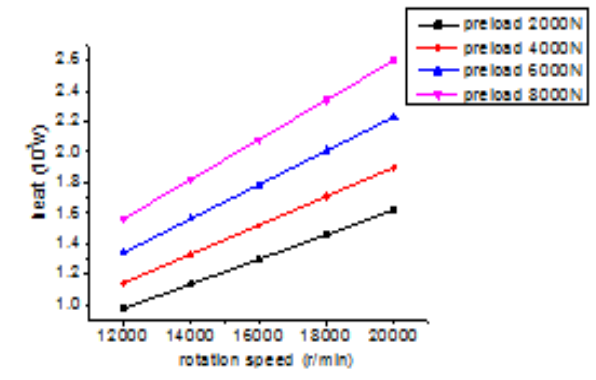

Figure 1. Finite Effect of rotation speed on bearing heart

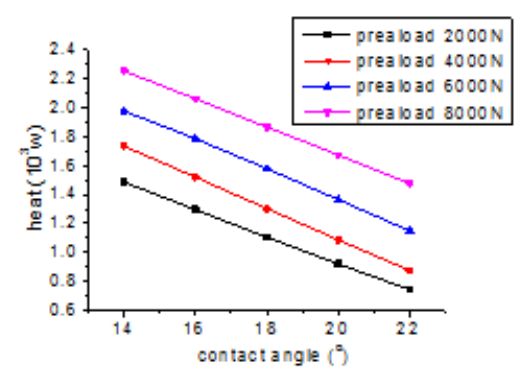

Figure 2. Finite Effect of contact angle on bearing heart

According to the calculation of bearing heat generation model, Fig. 1 shows the influence of the rotational speed on the bearing heat under different preload forces. It can be seen from Fig. 1 that the bearing heat increase obviously when the rotational speed changes. The main reason is that the loads between the ball and the raceways increase with the increase in the preload of bearing, and there is more heat generation due to friction in the bearing. The rolling components of contact point of the rolling body and raceway, the spin component of contact point of the rolling body and inner race raceway are all increased with the increase in the rotation speed of bearing. The rolling and sliding friction force of rolling body increases, resulting in the increase of heat and temperature. Fig. 2 shows the influence of the contact angle on the bearing heat under different preload forces. It can be seen from Fig. 1 that when contact angle changes, the bearing heat decreases is obviously. With the increase of the preload force, the increase of the bearing heat can be seen. Under different preloading, the trend of bearing heat change is similar. It is because that with the increase in contact angle of bearing, the resultant forces and contact stresses between the balls and raceways which loaded the axial force and radial force at the same time decrease. Thus, the heat generations in the bearing due to friction will decrease.

Heat Transfer and Heat Dissipation of Angular Contact Ball Bearing. The boundary conditions of bearing heat dissipation mainly include: ambient temperature, convection heat transfer between bearings and oil air lubrication and compressed air, convection heat transfer between bearing system and air. Under the condition of neglecting the heat radiation, the power loss (calorific value) of the bearing is finally dissipated by heat conduction and convection heat transfer. The convection heat transfer coefficient has a significant impact on the calculation results.

Oil-air lubrication for bearing system, the amount of oil used for oil and gas lubrication is very small, so the heat absorbed by the lubricating oil is negligible. Assuming that the heat exchange occurs only between the bearing and the compressed air, the compressed air is ejected to the bearing.

The convective heat transfer coefficient of the bearing and compressed air is the function of the spindle speed and the air flow, and can be fitted with polynomial function:

$$
\alpha=c_{0}+c_{1} u^{c_{2}}
$$

Where, $(u)$-Average velocity of air; $\left(c_{0}, c_{1}\right.$ and $\left.c_{2}\right)$ - measured by the constant [4], to take 9.7, 5.33 and 0.8 respectively.

When a bearing rotates at a certain speed, the convection heat transfer coefficient of the bearing with the air is:

$$
h=\frac{N k_{a i r}}{d}
$$

Where, $(h)$ - Convective heat transfer coefficient of air and surface of part; $(N)$ - nusselt number; $\left(k_{\text {air }}\right)$ - thermal conductivity of air; $(d)$ - diameter of cylindrical surface. 


\section{Numerical Simulation and Analysis of ANSYS}

In this paper, the temperature analysis of the bearing is coupled with the structural analysis when the ANSYS Workbench is used for the thermal analysis of the bearing. The basic operation steps include establishing three-dimensional models, defining material properties, mesh division, adding thermal load and boundary conditions, thermal analysis and viewing results. If it is unreasonably returned to the definition of the material attribute step to optimize the simulation parameters. The bearing model is introduced into Workbench in UG 3D modeling software, and the integrity of the model is checked and the material properties and structural units are defined. Fig. 3 is the mesh division of the Workbench analysis model of angular contact ball bearings, in which 14464 units and 58432 nodes are generated.

Based on the above calculation, the steady state thermal analysis of the angular contact ball bearing is carried out. The preload is respectively $2000 \mathrm{~N}, 4000 \mathrm{~N}, 6000 \mathrm{~N}, 8000 \mathrm{~N}$, the rotation speed is respectively $12000 \mathrm{r} / \mathrm{min}, 14000 \mathrm{r} / \mathrm{min}, 16000 \mathrm{r} / \mathrm{min}, 18000 \mathrm{r} / \mathrm{min}, 20000 \mathrm{r} / \mathrm{min}$ and the contact angle is respectively $14^{\circ}, 16^{\circ}, 18^{\circ}, 20^{\circ}, 22^{\circ}$. Because the friction factors are taken into account in the calculation process above, the contact way between rolling body and raceway is "bound" contact in thermal analysis. The outer ring is stationary, Rotation are applied on the inner ring. Fig. 4 shows the angular contact ball bearing temperature distribution with a preload of $2000 \mathrm{~N}$, rotation speed of $12000 \mathrm{r} / \mathrm{min}$ and contact angle of $14^{\circ}$. It can be seen from Fig. 4 that the maximum temperature is $58.339^{\circ} \mathrm{C}$, which is located in the contact area between the ball and the inner ring raceway. The outer ring of the bearing is basically the same as the environmental temperature. This is because the inner ring heat dissipation is poor, and the outer ring heat dissipation is relatively good.

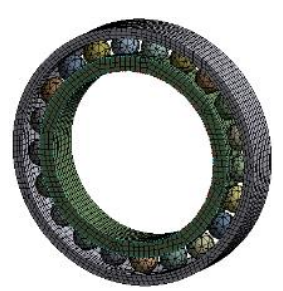

Figure 3. Finite Mesh division of angular contact ball bearing

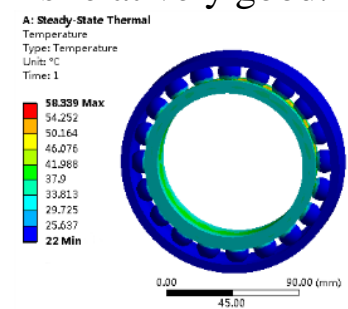

Figure 4. Finite Temperature distribution of angular contact ball

In order to study the influence of rotation speed and contact angle on the temperature of high-speed angular contact ball bearings under different preload conditions, multiple sets of date are simulated by Workbench, and the simulation results were summarized in Fig. 5 and Fig. 6. It can be seen from the figure that the maximum temperature of the bearings under different preload is approximately the same with the change of rotation speed and the contact angle. The increase of preload and rotation speed will result in the maximum temperature rise of bearings. The increase of contact angle can reduce of the maximum temperature of bearings, which is almost the same as that of calculating the bearing heat generation above. The reliability of calculating the bearing heat of the bearing is verified.

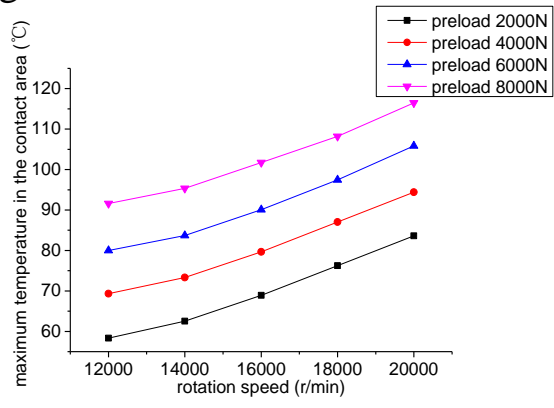

Figure 5. Finite Effect of rotational speed on maximum temperature in the contact area

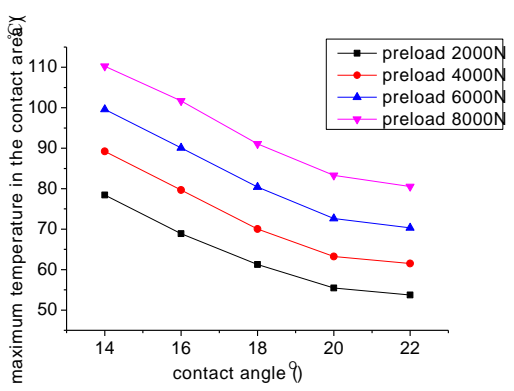

Figure 6. Finite Effect of contact angle on the maximum temperature in the contact area

\section{Conclusions}


From the numerical simulation results, the increase of preload makes the heat of friction increase, and then affects the temperature distribution of the bearing. At the same time, the contact angle and rotation speed will also affect the temperature distribution of bearing. A comprehensive analysis shows that when the angular contact ball bearings are running at high speed, the preload is too large to cause the bearing temperature to rise over the standard. If the preload is too small, the stiffness of bearing will be reduced. Therefore, the preload of the bearing shall be improved as far as possible in the temperature permission range. In this paper, the temperature characteristic analysis of rolling bearings under the influence of preload can be used as the basis for further detailed research of bearing temperature field, which has a good reference value for bearing design and research.

\section{Acknowledgements}

The authors gratefully thank the Natural Science Foundation of Henan Province of China (No. 162300410064) for financial support. This work is also supported by the Program for Innovative Research Team (in Science and Technology) in University of Henan Province (No. 15IRTSTHN008).

\section{References}

[1] X.W. Liu, W. Wang, Q.L. Wang. Analysis of temperature field of high speed angular contact ball bearing based on ANSYS[J]. Combined Machine Tool and Automatic Machining Technology, 2015(3): 13-15. (In Chinese)

[2] W. Bian, Z. Wang, J. Yuan, et al. Thermo-mechanical analysis of angular contact ball bearing [J]. Journal of Mechanical Science and Technology, 2016, 30(1): 297-306.

[3] F. Yu, S.S. Li, J. Shao, et al. Thermal and temperature field analysis study of high-speed angular contact ball bearing [J]. Industrial Control Computer, 2015(8):120-121. (In Chinese)

[4] G.C. Chen, L.Q. Wang, L. Gu, et al. Heat generation analysis of high speed ball bearing [J]. Journal of Aerospace Power, 2007, 22(1):163-168. (In Chinese)

[5] P. Wang, C.L. Lei, B.C. Zhou, et al. Finite element analysis for thermal characteristics of high speed angular contact ball bearing[J]. Applied Mechanics \& Materials, 2013, 397-400: 126-130.

[6] Z. Ye, L. Wang, G. Chen, et al. Analysis of thermo-mechanical coupling of high-speed angular-contact ball bearings[J]. Advances in Mechanical Engineering, 2017, 9(6): 168781401770281 .

[7] Q.G. Sun, Y.F. Wang, Y. Wang, et al. Numerical study on rolling bearing temperature field under the oil-air lubrication[J]. Applied Mechanics \& Materials, 2014, 487(487): 580-584.

[8] S.F. Jiang, Z.S. Liu, M.X. Yang. Pre tightening technology of angular contact ball bearings[J]. Bearing, 2003(3):1-4. (In Chinese)

[9] S.H. Li, M.H. Feng. Research on preload force technology of high speed spindle bearing[J]. Development and Innovation of Mechanical and Electrical Products, 2014, 27(3):165-167. (In Chinese)

[10] Peng L, Shizhao N, Zheng W, Ziwei J, Jianwu Y, Zhongxiang Q, Wangmo P. Predicting durations of online collective actions based on Peaks' heights [J]. Communications in Nonlinear Science and Numerical Simulation. 2018, 55: 338-354.

[11] S.E. Deng, Q.Y. Jia and J.X. Xue: Design Principle of Rolling Bearing (Standards Press, China 2014). 